\title{
Physician and government disconnect is becoming a chasm
}

The views expressed in this editorial are those of the author and do not necessarily reflect the position of the publisher.

$\mathrm{t}$ seems like it is getting harder to practise medicine in Canada. It seems more difficult every month, and that should not be the case. Normally Canadian physicians have been fairly trusting of government oversight and involvement in the management of health care. In fact, our system depends on it. We have relied on 2-way communication to make the system work. So why is there an increasing gap between physician needs for patient care and the rationing of health care dollars from the health departments?

Communication has definitely broken down in Ontario. You would think that having a physician as a health minister would help communication, but this did not seem to be the case in that province. The lack of leadership in the Ontario Medical Association (OMA) has allowed the Ontario government to circumvent physician input in order to put forward a plan that will only hurt patients. The ruling was headed off at the last minute by a group of doctors, the Coalition of Ontario Doctors, acting as the OMA executive should have been acting: ensuring future care for patients. The Health Minister, Eric Hoskins, who is 1 of 3 provincial health ministers who are doctors, had planned to freeze the envelope for health care in the face of an aging populace, a growing population and the need for more services. He was expecting the system, which is already not functioning adequately to care for the current patient population, to continue without any provision for expanded care. This is not exactly the kind of forward-thinking vision we need in Canada right now, and I am not sure whether this is the battle that the health ministry of Ontario wants to undertake. While physicians are worried about patient care, the government is focused on a health system envelope freeze in order to keep the budget on track. The current Ontario government has shown its inability to handle infrastructure, electricity, economic growth and the Ontario pension plan. The CancerCare Ontario scandal, the Ontario Health Premium and eHealth problems give us little hope that the government can do better in the health field.

Is the problem localized to Ontario? Probably not. The truth is more than one-third of Canadian doctors practise in Ontario; what happens in Ontario affects all of us. The realization that $80 \%$ of physicians in Nova Scotia voted in favour of an agreement that probably will not even cover cost of living increases is yet another example of the increasing mistrust that doctors have in the negotiation process.

Oversight and meddling from the federal government is not going to help the process or patient care. Health care, for better or worse, is a provincial mandate. The federal government should not be allowed to try making political gains by earmarking specific programs, such as home care. Rumors of the federal government threatening withdrawal of transfer payments if private health care continues to expand are extremely disconcerting. It is obvious to anyone who wants to save health care that privatization of certain services is necessary to save the public system. Provincial decisions need to be made with foresight and intimate knowledge of local health care conditions - they should not be determined by the "head in the clouds" federal government decades removed from the nuts and bolts of patient care. I also await the long-delayed (by government) Brian Day case in British Colombia. A seemingly easy legal decision of endangerment of patient health by the current rules should open the door to reconfiguring the health care systems to meet today's realities.

Overall there are certainly signs that the health care system is not in good health. The physicians who provide care have been marginalized with unilateral decisions at all levels of government. The population has recently become more critical of the doctors, seeming to blame doctors for poor access to health care despite high wages. The Ontario physicians at least have an active subgroup attempting to effect positive change in health care decision-making, but all across the country there should be concern over heavy-handed administrative decisions. It is time for physicians at large to recoup their rightful place alongside the government in decision-making for health care delivery in this country.

\section{Edward J. Harvey, MD \\ Coeditor, Canadian Fournal of Surgery}

Competing interests: E.J. Harvey is the Chief Medical Officer of Greybox Healthcare (Montreal) and Chairman of the Board of NXT-Sens Inc. (Montreal).

DOI: $10.1503 /$ cjs.012116 